Points

\section{Uptake of immunisation}

Dr Gillian Sleight (Community Health Offices, Radcliffe Infirmary, Oxford OX2 6HE) writes: Congratulations to Drs Angus Nicoll and Douglas Jenkinson for showing so clearly that $99 \%$ of children should be immunised against measles and $93-96 \%$ against whooping cough ( 6 August, p 406). If this common sense scheme were widely followed the rate of uptake would shoot up. Poor rates of immunisation are caused not by social deprivation as stated by Professor Brian Jarman and others (25 June, p 1775) but by the lack of knowledge of these simple facts by doctors and nurses. Professor Jarman and others found that "even allowing for social conditions the uptake of immunisation against diphtheria varied from $15 \%$ below . . to to $10 \%$ above the predicted values." Why? Professional knowledge, enthusiasm, and organisation have been shown to correlate well with uptake. ${ }^{1}$ Mothers in general wish to protect their children and need good advice. In Oxfordshire there is no correlation between low uptake and relative social disadvantage at electoral ward level. Professional disinterest and disorganisation should not hide under the cover of social deprivation.

1 Begg N, White J. A survey of preschool immunisation programmes in England and Wales. London: Public Health Laboratory Service Communicable Disease Surveillance Centre, 1987.

\section{Heart disease in Asians in Britian}

Dr StePhen HEad (Newark, Nottinghamshire NG22 9SZ) writes: In discussing the excess prevalence of ischaemic heart disease among Asians in Britain Drs Kim M Fox and Leonard M Shapiro do not mention the previous evidence suggesting a link between early environment and the risk of atheromatous diseases in middle life. Maternal mortality has been shown to be a predictor of future stroke and to correlate with coronary disease ${ }^{1}$ and it is well recognised that within Britain today heart disease is more common in those patients whose early life was spent in an area where poverty was more common. It seems that adverse social factors in early life increase the risk of heart disease, which would make sense from the known poverty in much of the Third World, whence the immigrants came. How poverty predisposes (and affluence protects) against heart disease is a fascinating question and the authors do propose one hypothesis: a qualitative difference in the atheromatous plaques. Perhaps an affluent lifestyle and diet in early life lead to the development of more stable plaques with a firmer foundation and therefore less liability to rupture. This hypothesis has grave implications for current thinking on diet in early life, implying that the current trend to a low fat, low protein diet in childhood may be counterproductive. Certainly among the present generation of native British patients with heart disease the "high carbohydrate low everything else" diet typical of the poor British family in the 1920s and '30s seems to be a predisposing factor. Studies on the relation between early diet and the subsequent risks of ischaemic heart disease are urgently needed. Until such information is available it is imprudent to assume uncritically that a diet that is healthy for a middle aged man will be beneficial for a young child.

1 Barker DJP, Osmond C. Death rates from stroke in England and Wales predicted from past maternal mortality. $\mathrm{Br}$ Med $\mathcal{f}$ 1987;295:83-6.

Dr HARPReET S KoHLi (Greater Glasgow Health Board, Glasgow G2 4JT) writes: The editorial by Drs Kim $M$ Fox and Leonard $M$ Shapiro reviewing coronary heart disease among "Asians" (people whose origin is the Indian subcontinent) in Britain is a timely one ( 30 July, p 311). It must be hoped that health care workers will now recognise this as a major problem for the Asian population in Britain. ${ }^{1}$ There are, however, some criticisms of the editorial that need to be noted. It should be recognised that the term "Asian" is one of convenience and needs to be accurately defined. ${ }^{23}$ Further, it is incorrect to state that "About one million immigrants from the Indian subcontinent live in Britain" because a significant proportion of them have been born in Britain and they are not immigrants. It would be correct, however, to say that about one million people of Indian subcontinent origin live in Britain. Finally, the authors' assertion that "smoking is probably less common among Asian men" needs to be qualified: smoking is probably less among some "Asian" men such as Sikhs but may be common among other groups such as "Asian" Moslems. ${ }^{4}$ These are not merely semantic points, rather they underline the need for accuracy and precision in medical writing.

1 Kohli HS. The health of "Asians" in Britain-a brief review. National Medical fournal of India 1988;1:27-30.

Shaunak S, Lakhani SR, Abraham R, Maxwell JD. Differences among Asian patients. Br Med f 1986;293:1169.

Bhopal RS. Respiratory illness and home environment of ethnic groups. Br Med f 1988;297:69.

4 Bhopal RS. Asians' knowledge and behaviour on preventive health issues: smoking, alcohol, heart disease, pregnancy, rickets, malaria prophylaxis and surma. Community Med 1986;8:315-21.

\section{Bovine spongiform encephalopathy}

Dr J C M ShARP (Communicable Diseases (Scotland) Unit, Ruchill Hospital, Glasgow G20 9NB) writes: Dr T A Holt and Ms J Philips (4 June, p 1581; 9 July, p 133) draw attention to the possibility of human infection from tissues of animals affected with bovine spongiform encephalopathy. The emergence of this "new" disease has been regarded with considerable concern, and the government has rightly made the disease notifiable in cattle and taken measures to prevent feeding of animal protein to cattle. After an interim report from the working party on bovine spongiform encephalopathy the minister of agriculture, fisheries, and food announced on 7 July that the government had accepted that "as a precautionary measure carcases from affected cattle should be destroyed." By making this announcement the government has accepted that there is at least a theoretical risk of human infection. It is therefore somewhat surprising that to date (1 August) no action has as yet been taken and that affected cows are still being slaughtered and are entering the human food chain.

\section{Restless leg syndrome}

Dr Christian von SCHÉELE (Department of Medicine Sjukhuset, S-831 83 Ostersund, Sweden) writes: D J $M$ Pearce answered a question about the safety of treating the restless leg syndrome with Sinemet (levodopa) (23 July, p 278). Such treatment was apparently favourable in the subject referred to, a man in his $70 \mathrm{~s}$. Dr Pearce did not, however, fully respond to the question. We agree with him that levodopa is bes confined to patients with parkinsonism, but there are two studies that indicate the usefulness of levodopa in treating the restless leg syndrome. ${ }^{12}$ Indeed, levodopa was suggested as the drug of choice in a leading article in the $B M \mathcal{F} .{ }^{3}$ We have used levodopa in about 30 patients with this syndrome for at least two years. Currently no adverse reactions have been observed.

1 Akpinar S. Treatment of restless leg syndrome with levodopa plus benserazide. Arch Neurol 1982;39:739.

von Scheele C. Levodopa in restless legs. Lancet 1986;ii:426-7.

3 Clough C. Restless legs syndrome. Br Med f 1987;294:262-3.

\section{Health and the ozone layer}

Dr E S ShEarer (Liverpool Maternity Hospital, Liverpool L7 7BN) writes: In their editorial Drs Rona M MacKie and Michael J Rycroft list a few of the commoner sources of that scourge of the environmentchlorofluorocarbons (6 August, p 369). The fact that the ozone layer is being systematically destroyed, mainly by the widespread use of aerosols, is generally accepted. The medical profession should, however, shoulder some of the blame. In 1951 Suckling manufactured a chlorofluorocarbon that was to revolutionis anaesthesia-halothane. Over the past 30 years halothane and its related agents enflurane and isoflurane (also chlorofluorocarbons) have been used in countless millions of anaesthetics. A simple calculation shows that one minute of anaesthesia with $0.5 \%$ halothane in a fresh gas flow of $8 \mathrm{l} / \mathrm{min}$ releases about $10^{21}$ halothane molecules. (With halothane up to $20 \%$ of this may be metabolised. With isoflurane the proportion met abolised is much smaller, in the region of $0.2 \%$.) This number of molecules of a chlorofluorocarbon will according to Drs MacKie and Rycroft, destroy $10^{2}$ ozone molecules. This is after just one minute of an anaesthetic at a low concentration. Multiply this by the number of anaesthetics administered world wide and we seem to have a major pollution problem. Much effort has gone into improving the operating theatre for the benefit of staff. One method of achieving this is to vent waste anaesthetic gases directly to the outdoors. This may well improve the atmosphere inside the theatre but does little for the atmosphere outside. Perhaps greater awareness of this problem will act as a spur towards the greater use of total intravenous anaesthesia, thereby avoiding the use of these environmentally noxious agents.

\section{Ultrasound screening and abdominal aortic aneurysm}

Mr R A P ScotT (St Richard's Hospital, Chichester, West Sussex PO19 4SE) writes: I thank Mr Jack Collin for pointing out that aortic aneurysms are much commoner in men than in women (30 July, p 360) Anyone setting up a screening programme should concentrate on men between the ages of 65 and 80 . O the 102 patients with an aortic diameter of $3 \mathrm{~cm}$ or more, 84 were men. Our study is aimed at giving these basic data so that decisions on the most favourable group to screen can be made. As our programme progresses the criteria for considering operation in those screened with ultrasonography will become available.

\section{Voluntary drug rationalisation programmes}

Professor J R Trounce (Pharmacy Drug Information Department, Guy's Hospital, London SEl 9RT) writes: We in Lewisham and North Southwark were surprised (as were no doubt our colleagues at The London, Royal Free, King's College, St Georges, S Mary's, and Charing Cross Hospitals) to read the comment in Editor's Choice (13 August) that no London teaching hospital other than the Westminster had used voluntary drug rationalisation programmes. Our district drug formulary was first introduced in 1984 and has been operating on a similar basis to that described by $\mathrm{Mr}$ John A Baker and others (13 August, p 465). As with the Westminster scheme compliance and savings have been carefully monitored, and ou scheme has been as successful. In our view the key to success is the close participation of doctors and pharmacists throughout the project.

\section{Academic freedom at the MRC}

Dr D A ReEs (Medical Research Council, London WIN 4AL) writes: Minerva is talking through her helmet ( 30 July, $p 368$ ). The specific points to which she refers in the Lancet about academic freedom have been answered in its correspondence columns. 'As for "scolding" or "bullying" I have to admit to a belief in direct discussion when differences of opinion exist on important matters. I have the impression that those senior academics and Medical Research Council staff with well formed and strongly held views very much prefer it that way.

1 DA Rees. Academic freedom and the MRC. Lancet 1988;ii:339.

\section{Correction}

\section{Uptake of immunisation}

An editorial error occurred in this letter by $\mathrm{Dr} \mathrm{J} \mathrm{A}$ Reid (13 August, p 484). The last two parts of the key to the figure were transposed. The figure should show that in areas $\mathrm{C}, \mathrm{D}, \mathrm{E}$, and $\mathrm{H} 70-79 \%$ of children completed courses of immunisation against diphtheria (not $80-89 \%$ as published) and that in areas F, I, K, and $\mathrm{T} 80-89 \%$ of children completed the courses (not $70-79 \%$ as published). 